\title{
Komunikasi Antar Persona Ibu dan Anak Bertato
}

\author{
Ivan Surya, Wulan Purnama Sari \\ ivannsurya@gmail.com,wulanp@fikom.untar.ac.id \\ Fakultas Ilmu Komunikasi Universitas Tarumanagara
}

\begin{abstract}
The study was conducted to find out how interpersonal communication or interpersonal communication occurs between mother and child tattooed. This research is to find out the changes in communication between persons between a mother and her child after and before having a tattoo. The approach in this study is a qualitative approach with the method used in the phenomenology method. Data collection obtained is through three ways, namely documentation, observation, and also deeper interviews with a source. The researcher concluded in this study that communication between persons that occurs from each speaker is different. And every mother will accept her child back to normal even though her child has done something negative or bad. The strongest reason a mother forbids her child from having a tattoo is not to get sick or damage the skin and body, which can be concluded that every mother is more concerned with the health of her child.
\end{abstract}

Keywords : Relationships, Tattoo, Person to Person Communication

\begin{abstract}
Abstrak
Penelitian ini dilakukan untuk mengetahui bagaimana komunikasi antar persona atau komunikasi interpersonal yang terjadi antara ibu dan anak bertato. Apakah terdapat perubahan dalam komunikasi antar persona antara seorang ibu dengan anaknya, sesudah dan sebelum mempunyai tato. Pendekatan dalam penelitian ini adalah pendekatan kualitatif, dengan metode fenomenologi. Pengumpulan data yang didapat adalah melalui tiga cara yaitu dokumentasi, observasi, serta wawancara mendalam. Peneliti menyimpulkan bahwa komunikasi antar persona yang terjadi pada setiap narasumber berbeda-beda. Seorang ibu akan menerima anaknya kembali seperti semula walaupun anaknya sudah berbuat hal yang negatif atau buruk. Alasan terkuat seorang ibu melarang anaknya untuk mempunyai tato adalah supaya tidak terkena penyakit atau merusak bagian kulit dan tubuhnya. Hal ini karena ibu lebih mementingkan kesehatan anaknya.
\end{abstract}

Kata Kunci : Hubungan, Tato, Komunikasi Antar Persona

\section{Pendahuluan}

Friedman (2010) mengemukakan bahwa keluarga terdiri dari ibu dan ayah yang merupakan seorang guru dan contoh paling utama untuk seorang anak. Pasalnya, orang tua dari awal sudah menginterpretasikan tentang masyarakat dan juga dunia kepada seorang anak. Orang tua terdiri atas seorang ayah dan juga seorang ibu yang menghasilkan keturunan yaitu anak. Anak atau remaja adalah suatu masa dimanaindividu dapat berkembang dari seperti pertama kali menunjukan suatu tanda seksual sekunder sampai mencapai suatu kematangan seksual. Pola identifikasi dari anak-anak hingga dewasa dan psikologisnya mengalami perkembangan karena peralihan dari ketergantungan yang menyangkut sosial dan ekonomi penuh dalam keadaan relatif lebih mandiri (Sarwono, 2010). 
Sedangkan menurut Friendly (2002), komunikasi yang terjadi dalam suatu keluarga dapat dikatakan bahwa itu adalah sebagai bentuk dalam kesiapan untuk membicarakan sesuatu dengan apa adanya tentang hal apapun dalam keluarga baik yang tidak menyenangkan maupun hal yang menyenangkan. Pembicaraan dilakkan dengan rasa kejujuran, keterbukaan, dan juga kesabaran agar dapat menyelesaikan masalah-masalah yang terjadi dalam keluarga.

Chodriyah (2017) memaparkan bahwa dengan berkembangnya zaman maka pandangan dan budaya dari tato mulai mengalami perbedaan seperti arti dari tato tradisional adalah sesuatu yang bersifat magis dan juga religius karena gambar pilihan merupakan sebuah ilustrasi dari setiap kebudayaan dalam masyarakat setempat. Pada zaman sekarang ini tato tidak lagi dipandang sebagai sesuatu yang bersifat religius tetapi malah memunculkan stigma yang negatif. Kemudian pada Orde Baru, tato dianggap dekat dengan kriminal dan masyarakat berpendapat bahwa orang yang memiliki tato adalah penyakit dalam sebuah lingkungan masyarakat dan harus disingkirkan agar tercipta keamanan dan juga ketertiban dalam masyarakat. Menurut Gumilar, belakangan ini mengalami pergeseran kembali yaitu tato sudah menjadi model. Apabila semula tato adalah bagian dari budaya ritual etnik tradisional kini sudah berkembang menjadi bagian dari budaya pop.

Azeharie dan Setiawan (2017) melakukan penelitian berjudul "Studi Komunikasi Antarpribadi Anak dengan OrangTua Tiri". Pendekatan dalam penelitian ini adalah pendekatan penelitian deskriptif kualitatif. Data primer diperoleh dari hasil wawancara dengan empat orang anak dengan satu orang tua tiri, dan data sekunder diperoleh dari data yang didapat dari buku dan sumber data lainnya seperti penelusuran sumber online. Hasilnya bahwa anak yang tahu dan mengetahui seorang calon orangtua tiri sebelum menikah dengan orangtua kandungnya adalah hubungan yang relatif lebih baik dibandingkan dengan anak yang tidak mengetahui calon orang tua tirinya sebelum orang tua kandungnya menikah. Dalam penelitian memiliki kesamaan dengan penelitian penulis karena metode yang digunakan sama yaitu observasi dan juga wawancara untuk mendapatkan suatu data. Sedangkan perbedaannya adalah penelitian yang diteliti oleh penulis adalah dengan orang tua kandung.

\section{Metode Penelitian}

Menurut Edmund Husserl (dalam Hadiwijono, 1995), fenomenologi berasal dari bahasa Yunani yang berarti fenomenon yaitu sesuatu yang terlihat atau tampak karena bersinar serta dalam bahasa Indonesia biasa disebut dengan gejala. Gejala seringkali dipertentangkan dengan hal lain yang nyata melainkan itu semu atau dapat juga dikatakan dengan kenyataan. Sisi lain kata fenomenon ditempatkan sebagai lawan dari objeknya sendiri hingga bertemu dengan bentuknya sebagai bagian dari tampakan.

Penulis ingin mengetahui bagaimana hubungan komunikasi yang terjalin antara ibu dan anaknya yang bertato. Penelitian ini menggunakan pendekatan kualitatif dan disertai dengan wawancara mendalam terhadap narasumber. Metode yang digunakan adalah fenomenologi, bertujuan agar dapat memberitahu komunikasi antar persona yang terjadi antara seorang ibu dengan anak yang bertato sebab metode ini sangat dekat kealamiahan atau bisa dikatakan juga tidak mengubah apapun seperti tampak ada adanya. 
Pendekatan yang dipilih oleh penulis adalah kualitatif karena data-data atau informasi diperoleh melalui beberapa narasumber yang bersangkutan. Penulis berharap penelitian ini dapat menjelaskan atau memberitahukan bagaimana hubungan komunikasi interpersona yang terjadi antara seorang ibu dengan anak yang bertato secara lebih mendalam dan juga dapat berguna bagi para pembaca. Teknik pengumpulan data yang dipakai adalah observasi, metode teknik wawancara, dan juga dokumentasi untuk memperkuat suatu informasi atau data yang sudah diperoleh.

Suyatna (2005) mengatakan bahwa narasumber adalah peran dari seorang narasumber atau informan dalam mengambill data yang akan dicari tahu melalui orang-orang tertentu yang mempunyai nilai dalam menguasai suatu persoalan yang akan diteliti atau juga memiliki keahlian dan juga wawasan yang cukup. Dalam penelitian ini yang menjadi subjek adalah orang tua dan yang menjadi objeknya adalah anak yang bertato.

Analisis data yang penulis gunakan ialah analisis data kualitatif yang berarti proses pencarian data dan penyusunan hasil data dari wawancara, dokumentasi lapangan, dan pula sumber lain secara sistematik agar lebih mudah tersampaikan dan dipahami oleh seorang pembaca.

Dalam teknik ini, penulis memverifikasi data dengan melalui pengecekan dan membandingkan antar sumber data yang didapat. Peneliti mencoba mencari lagi narasumber lain ataupun sumber lain di luar data yang telah dimiliki.

\section{Hasil Temuan dan Diskusi}

Penulis menemukan bahwa terdapat stigma bahwa tato hanya terdapat pada badan seorang kriminal ataupun perlakukan tak bermoral lain. Tato seakan menjadi tanda terhadap kriminal di Indonesia pada waktu penembakan misterius pada sekitar tahun 1980. Badan yang bersih dari tato pun turut menjadi standar bagi jiwa yang bersih. Clinton Sanders, seorang sosiolog asal Amerika Serikat menyatakan bahwa tato berfungsi untuk mempresentasikan identitas yang berarti bisa amat bervariasi antar tato. Gambar diciptakan pada tubuh manusia untuk dekoratif, relijius, dan simbol tertentu.

Penulis mewawancara tiga pasang narasumber dalam penelitian ini. Stephanus David menjadi narasumber pertama peneliti. Barista di salah satu mal yang berada di pusat kota Jakarta ini memberi penjelasan alasan memberi tato pada tubuhnya. Alasannya adalah ia berkeinginan memberi cerita riwayat hidup pada tubuhnya melalui lukis tato. Ia pun menambah bahwa tato yang terlukis adalah sesuatu yang ia sayangi dan percayai, seperti misalnya tato bertuliskan nama ibu angkatnya. Tato tersebut berada di pergelangan tangan kirinya yang memberi tanda rasa sayang pada ibunya. Tato bergambarkan kartu pada bagian kanan pinggang yang dimaksudnya untuk memberi arti hidup adalah sebuah perjudian. Ia melakukan tato pertamanya saat berumur 18 tahun ketika baru melewati masa SMA. Awalnya, ia tidak gentar terhadap kemarahan orang tua karena tidak setuju. Ia memiliki pandangan yang berbunyi bahwa permintaan maaf akan lebih baik dibanding permintaan izin. Jika sang orang tua pada akhirnya timbul rasa amarah, maka ia akan membujuk orang tuanya dengan berperilaku baik, bukan membiarkan sambil berharap waktu akan memperbaiki situasi ini dengan sendirinya. Ia sendiri sebenarnya telah mengetahui ketidaksetujuan ibunya jikalau terdapat lukisan tato berukuran besar dan dalam jumlah banyak pada tubuhnya. Hal itu dianggap dapat mempersulit untuk melamar pekerjaan. Ditambah lagi pandangan buruk dari orang. 
David berkeinginan ada perubahan stigma dalam masyarakat terhadap seseorang yang bertato sehingga terjadi perbedaan pada pandangan yang saat ini seakan sinis. Penulis juga mewawancarai sang ibunda, Jeannete. Sang ibunda pun tidak terlalu mempersoalkan jika ukuran tato tidak besar. Kaget dan marah merupakan respon pertama sang ibu ketika melihat David tiba di rumah dengan lukisan tato mengisi tangan kirinya. Jeannette hanya bisa memberi nasihat dan wejangan kepada Davis, agar sebaiknya tidak bertato agar tidak kesulitan mencari mata pencaharian. Sanak famili Davis pun tak memberi komentar maupun menyinggung tato sehingga tak masalah. Jeannete pun kini sebenarnya telah tidak memberi izin Davis untuk memberi tambahan tato pada tubuhnya. Menurut Jeanette, saat ini tato yang ada telah teramat banyak. Jeannet mengikhlaskan peristiwa ini asalkan dengan satu syarat, tidak lagi menambah tato.

Narasumber kedua, Marcel Budiman. Awal memiliki tato adalah keinginan untuk mengikuti teman-teman. Kemudian ia mencoba tato temporer yang tidak permanen dan dapat dihilangkan. Pada akhirnya, ia mencoba tato permanen. Ia tidak mempedulikan jika nanti sang ibu marah ketika tato. Hal yang diutamakan ialah ia telah mentato tubuhnya. Saat mengetahui anaknya menato tubuh, sang ibu marah dan diluapkan kepada Marcell. Ibunya pun mencakari tato pada tubuh Marcell. Marcell sendiri memilih diam menghadapi sang ibu hingga situasi dapat kembali seperti semula. Alasan kemarahan tersebut juga diketahui Marcel menurutnya adalah stigma yang terdapat pada masyarakat, terutama lingkungan keluarga misalnya sanak sudara yang seringkali memberi sindiran dan menjadikannya sebagai topik dalam pembicaraan. Hal tersebut pun seringkali membuat ibunya mengulangi kemarahannya kepada Marcel. Marcell menyatakan kalau pertama kali sekali mentato badannya pada kelas SMA 3 semester 2.

Sedangkan data yang didapat dari ibunya yang bernama Tan Yin Soei atau biasa di panggil dengan Ibu Susi, saat pertamakali mengetahui anaknya bertato, perasaannya panik. Anaknya tidak meminta izin karena anaknya menyadari tidak akan memperoleh izin mentato tubuhnya. Padahal Ibu Susi lebih menyukai apabila Marcell meminta izin terlebih dahulu, walaupun tetap tidak diberi izin, daripada mentato badannya secara diam diam dan dimarahi habis-habisan. Marcel tidak ada usaha untuk berbaikan atau mengajak bicara ibunya. Ia memilih untuk diam dan seiring berjalannya waktu emosi sang ibupun mereda. Pertama kali sang Ibu mengetahui bahwa Marcell telah bertato adalah pada saat Marcell tertidur dengan sangat pulas di kamarnya dengan tidak memakai busana. Saat itu, pintu kamar tidak dikunci dan kemudian sang ibu masuk ke kamarnya dengan maksud untuk melihat keadaan sang anak.

Saat ini, ibu Susi tidak pernah mengizinkan Marcell untuk menambah tatonya lagi tetapi dia malah mengharapkan bahwa sang anak dapat menghapus atau melunturkan tatonya dengan menggunakan cara apapun. Alasan paling kuat dan paling spesifik Ibu Susi sangat melarang anaknya untuk mempunyai tato adalah karena apabila nanti sudah tua maka bagian kulit akan mengalami keriputan dan kulit kulit yang tertimpa dengan tato akan terlihat sangat jelek, kotor dan kusam. Sepengetahuan Ibu Susi bahwa cara untuk menghapus atau menghilangkan sebuah tato adalah dengan menggunakan alat setrikaaan yang panas dan dirinya sangat takut bahwa nanti kulit anaknya akan menjadi rusak yang berarti bahwa dirinya sangat atau lebih mempentingkan kesehatan anaknya. Pertimbangan kesehatan ini bahkan lebih daripada kekhawatiran anaknya yang bertato sulit mendapatkan pekerjaan atau dipandang sebelah mata oleh sebagian orang. Ibu Susi juga menyatakan bahwa 
anaknya mendapatkan kerja atau tidak tergantung dari potensi atau skill anaknya sendiri sehingga itu bukan merupakan sebuah alasan yang terkuat kenapa dirinya melarang anaknya untuk mempunyai tato dan tidak akan pernahsekalipun mengizinkan anaknya untuk menambah tato lagi sampai dengan kapanpun.

Narasumber ketiga merupakan freelancer bernama Frangkie Darmawan. Ia menyukai tato itu karena melihat teman dan mulai ikut-ikutan temannya. Dalam diri sendiri ia berpendapat bahwa mempunyai tato adalah suatu hal yang keren. Pada awalnya, semua tato Frangkie adalah gambar-gambar yang dipilih oleh dirinya sendiri yang menurutnya gambarnya bagus serta tidak memiliki sebuah arti tetapi sekarang tato-tato yang ditambah olehnya mempunyai sebuah arti.

Pada awalnya dia sangat ragu untuk mentato badannya dengan alasan bahwa dirinya sangat takut apabila sang Ibu marah dan kemudian mengusirnya dari rumah apabila sang ibu mengetahui bahwa dirinya sudah bertato tetapi Frangkie memberanikan dirinya untuk mentatonya terlebih dahulu. Frangkie cuma bisa diam ketika ibunya mengetahui bahwa dirinya sudah mempunyai tato karena dirinya telah sadar dan mengakui kalau dirinya memang sudah berbuaat kesalahan. Dari awal Frangkie sudah mengetahui alasan mengapa sang ibu melarangnya untuk mempunyai tato yaitu karena takut merusak tubuh atau badannya serta terkena penyakit yang disebabkan oleh terinfeksi dengan jarum kotor dan jarum yang tidak steril. Jarum yang kotor dan jarum yang tidak steril adalah apabila seseorang ingin mentato anggota badannya tetapi menggunakan jarum yang sudah bekas atau yang sudah digunakan oleh orang lain terlebih dahulu maka itu dapaat menimbulkan sebuah penyakit.

Hasil wawancara dengan ibu dari narasumber ketiga ini, bernama Claudia, menunjukkan kekagetannya disertai perasaan kesal saat pertama kali mengetahui bahwa anaknya telah mempunyai tato. Pada mulanya, Frangkie mentato badannya secara diam-diam dan pada suatu hari dirinya lupa untuk membawa baju ganti ke dalam kamar mandi sehingga membuat dirinya harus keluar dari kamar mandi dengan tidak menggunakan pakaian dan hanya menggunakan handuk untuk menutupi tubuhnya dari bagian pinggang sampai betisnya. Pada saat itu, sang ibu langsung melihat dan tahu bahwa sekarang anaknya sudah punya tato. Sang ibu dan Frangkie pun tidak pernah bertengkar hanya karena masalah tato, Frangkie hanya sekedar membicarakannya dan berdebat.

Sanak saudara dari Frangkie tidak pernah sekalipun membahas dan membicarakan tentang tato. Frangkie dan ibunya Claudia tidak pernah peduli apabila sanak saudaranya membicarakan atau membahas tentang tato yang di tubuh Frangkie. Mereka berdua sudah sepakat tidak akan mendengarkannya baik oleh saudaranya maupun dengan orang lain yang tidak dikenal. Ibu Claudia sudah menerima keadaan dan pasrah serta memahami kondisi anak muda zaman sekarang ini sudah berbeda dengan anak muda zaman dulu. Sampai detik ini juga sang Ibu tidak akan pernah memberikan izin apabila sang anak ingin menambah tatonya lagi dan kemudian Ibu Claudia sudah membuat perjanjian dengan anaknya Frangkie bahwa bila Frangkie menambah kembali tatonya yang sudah banyak itu maka Ibu Claudia tidak akan pernah menganggap Frangkie sebagai anaknya lagi.

Ibu Claudia termasuk dalam kategori ibu yang termasuk santai dalam menghadapi dan mendidik anaknya karena beliau tidak mendidik anaknya dengan begitu keras dan ketat. Meski demikian, ia sangat menyayangi anaknya dan tidak menginginkan sesuatu hal yang buruk terjadi kepada anaknya maka dirinya akan 
selaluu kembali menerima anaknya dengan apa adanya setelah apa yang telah dilakukan oleh sang anak.

Wiryanto (2005) menyatakan bahwa ciri ciri komunikasi antar persona atau interpersonal bila dirangkum dengan data dari narasumber yang didapat yaitu seperti memenuhi ciri keterbukaan (openess) dimana ada kemauan untuk menanggapi komunikasi antar persona dalam hubungan yang interpersonal. Terdapat juga suatu empati (emphaty) yakni merasakan keinginan dari anaknya yaitu untuk mempunyai tambahan tato lagi. Dukungan (supportiveness) yang berupa suatu keterbukaan dalam komunikasi dengan menanyakan kabar dan memberikan wejangan atau nasehat. Lalu memberikan tanggapan positif (possitiveness) dengan tidak mempentingkan pandangan atau stigma yang negatif tentang tato.

Narasumber mengalami gangguan pada keterbukaan (openess) karena takut dengan amarah orangtua ketika mengetahui kalau diri mereka telah bertato. Namun hal ini hanya bersifat sementara atau tidak berlangsung lama. Kemudian tidak ada empati (empathy) dari sang ibu kepada anaknya yang ingin mempunyai sebuah tato. Dukungan (supportivenesss) dan perasaan positif (positvenesss) dari ibu membuka lagi keterbukaannnya sehingga dapat menimbulkan komunikasi kembali sebagaimana seutuhnya sebuah keluarga.

\section{Simpulan}

Tidak ada perubahan dalam komunikasi antar persona antara seorang ibu dengan anaknya yang bertato. Adanya perubahaan komunikasi antar persona hanya bersifat sementara atau berlangsung dengan jangka waktu yang tidak lama atau juga termasuk singkat. Tujuan yang ingin diketahui dalam penelitian ini adalah mencari tahu bagaimana komunikasi antar persona yang terjadi antara seorang Ibu dengan anaknya yang bertato.

Seorang ibu akan kaget, marah, dan kesal saat pertama kali mengetahuii bahwa sang anak terlah mempunyai sebuah tato tetapi itu tidak berlangsung lama dan kemudian sang ibu akan kembali menerima anaknya dan kembali berkomunikasi normal seiring dengan berjalannya waktu. Seburuk apapun kesalahan yang telah diperbuat oleh anaknya, seorang ibu akan selalu kembali menerima anaknya apaa adanyya dan terus berusaha menasehati dan merubah anaknya secara terus menerrus agart terus menjadi lebih baik lagi sehingga tidak akan berbuat atau melakukan hal yang negatif lagi di kedepannya.

Alasan terkuat, terspesifik, dan yang paling utama seorang ibu melarang anaknya untuk mempunyai tato agar terus menjaga kesehatannya dan tidak merusak badannya atau tubuhnya serta anggota tubuh lainnya karena terkena penyakit yang di sebabkan oleh jarum atau juga tinta tato yang tidak bersih dan juga tidak steril (kotor) dikarenakan setiap ibu pasti lebih mementingkan kesehatan anaknya dibandingkan dengan apapun. 


\section{Ucapan Terima Kasih}

Penulis mengucapkan terima kasih kepada semua narasumber yang bersedia untuk meluangkan sedikit waktunya untuk melakukan sesi tanya jawab atau wawancara dan juga memberikan banyak informasi kepada penulis selama prosess pencarian pengumpulan data di dalam penelitian ini. Penulis juga mengucapkan terima kasih kepada Fakultas Ilmu Komunikasi Universitas Tarumanagara dan juga seluruh pihak yang terkait dalam proses pembuatan penelitian ini.

\section{Daftar Pustaka}

Azeharie, Susy., \& Setiawan, Chaterine. (2017). Studi Komunikasi Antarpribadi Anak Dengan Orang Tua Tiri. Universitas Tarumanagara.

Chodriyah, Lailatul. (2017). Komunitas Gang Tatto Dan Stigma Masyarakat diakses pada hari Sabtu, 23 Februari pada pukul 19.00 WIB. Terarsip di : https://geotimes.co.id/opini/komunitas-gang-tatto-dan-stigma-masyarakat/

Friedman, M. 2010. Buku Ajar Keperawatan Keluarga : Riset, Teori, dan Praktek Edisi ke-5. Jakarta: EGC.

Friendly. (2002). Komunikasi dalam Keluarga. Family Altar: Jakarta.

Hadiwijono, Harun. Imam Kristen. Jakarta: BPK Gunung Mulia, 1995.

Pragota, Ardhana. (2017). Tato dan Mengapa Dia Dicap Buruk diakses pada hari Minggu, 14 Juli pada pukul 19.46 WIB. Terarsip di : https://kumparan.com/@kumparanstyle/tato-dan-mengapa-dia-dicap-buruk

Sarwono. 2010. Ilmu Kebidanan. Jakarta : PT. Bina Pustaka.

Sibuea, Bidari Medi. (2014). Penggunaan Tato Pada Masyarakat (Studi Terhadap Tato Sebagai Komunikasi Non Verbal). Universitas Indonesia.

Suyatna, Bagong. (2005). Metode Penelitian Sosial: Berbagai Alternative Pendekatan. Jakarta: Kencana Prenada Media Group 